\title{
推動公司僱員健體評劃的限制因素：
}

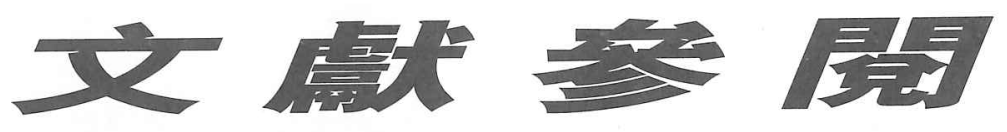

\section{Limiting Factors in Promoting Corporation Fitness Programs in Hong Kong: A Review of Literature}

\author{
鄭偉明 \\ 浸會大學體育系導師 \\ Cheng Wai Ming, Warman \\ Physical Eduaction Instructor, Department of Physical Education \\ Hong Kong Baptist University
}

\begin{abstract}
Corporations have begun to focus on introducing employees' health fitness programs because they realized that improvement of employees' health will result with increased productivity, better morale, raised job satisfaction, minimized absenteeism, enhanced stability of the work force, lowered turnover, reduced medical claims. In striving to deliver quality employees' fitness program in an effective manner, managers and program planners should be concerned with examining the factors that limit the promotion of employees' fitness programs. The limiting factors can be examined under two domains: supply (the corporations) and demand (employees) using Conceptual or Empirical methods.
\end{abstract}

\section{引 言离}

縱使香港在1997 年以後的經濟命運仍是未知之 數, 現在她在東亞南的商貿發展仍佔著一定的影響 力。為了提高經濟效益, 各大小公商機構均希望盡 量發揮其員工之生產力。

活躍的生活方式可提高生活的質素, 適量的活動 可增強體能而預防疾病和減慢身體老化的出現。運 動可增加人們對環境的適應能力, 更可增強自信而 舒緩壓力。再者, 運動可加強及促進人的集中力 (Bouchard et al, 1988; Greenberg, 1993)。

工商機構開始引進僱員健體計劃, 因為他們了解 到如果僱員的健康有所改善, 會令他們有更高的生 產力、更好的士氣、對工作更滿意、減低缺席率、 增強工作的穩定性、減低人材流失和節省醫療補助 (Bernacki \& Baun, 1984; Nordstrom, 1988 )。

\section{僱員健體計劃}

\section{意 念}

健體計劃的首要任務是提高僱員參與運動的興 趣, 特別是那些平常較少運動的文職人員。S t o n e (1995) 認為僱員健體計劃的主要目標在於參與而非
精英訓練, 要讓員工有較多的選擇。除了傳統的心 肺和力量訓練外, 更應設立交誼舞蹈或集體遊戲等 以吸引更多的參加者。這些體能需求較低的活動可 將一般文職員工的體能逐漸提高, 日後便可參加更 高水平的訓練 (Nordstrom, 1988)。

\section{肉容}

"Program mix"是形容健體計劃所能提供給僱員 不同層面的機會, 其中包括闊度和深度。闊度形 容其廣泛性, 而深度是指其能否改變那些深表抗 拒的員工。成功的大規模健體計劃要兩者兼顧。 如資源缺乏時便要作出取捨, 當然其質量便會受 到一定的影響。所以在設計時必須基於機構所定 下的目標和先決條件(Association for Fitness in Business (AFB), 1992)。

健體中心是推行健計劃時重要的一環。可作肌 肉功能和心肺耐力訓練的健身室當然是不可缺少 的, 其次是時下流行的健康舞室, 隨之是可進行營 養、戒煙、瑜珈、壓力處理等課程的房間。當然如 果可以設立受歡迎的網球場和壁球室, 甚至羽毛球 場、籃球場和排球場等, 員工就會有更多的選擇和 機會(Nordstrom, 1988)。

\section{管理方式}

個別的公司會有不同的架構去發展健體計劃。 在起步的階段, 健體計劃大多數是由個別職員或 部門去處理。小型公司通常會由執行秘書或行政 助理去辦理; 而較大型的機構, 會交由人力資源 部去負責。第二種情沉, 有些公司在擴大健體計 劃會聘請專業公司去承辦。此時, 最重要是在公 司與承辦者之間建立緊密而明確的溝通渠道。在 規模較大的機構, 更會設立獨立部門, 聘請專業 的職員來處理健體計劃的大小事務(AFB，1992)。

為確保僱員健體計劃有合理的回報，應定時 作檢討和研究。首先要準確地記錄各項支出如醫 療保險、行政費用等, 僱員的出席率等與士氣和 態度有關的資料亦要作適當的分析。 


\section{僱員健體計劃的好處}

現今社會是科學化的時代, 從前人手操作的工 序漸漸被電腦化的機械所取代, 人們工作時的體力 活動需求随之減低, 因而影響其身體健康。要提高 僱員的體能水平, 必須引進有系統的僱員健體計劃 以舒緩其心理壓力、減低情緒上的波動、消除不必 要的憂慮、減少健康上的問題、提高工作上的滿足 感而增加其促動力(Ruskin, Halfon, Rosenfeld \& Tenenbaum, 1990)。Stone (1995) 列出的僱員健體 計劃的效益有：提高生產力; 減低缺席率; 增強土 氣; 改善公司的形象而減少員工的投訴。

Shephard (1996) 總括52個有關僱員健體計劃的 研究後, 結論是參加者的體能均有所改善, 心臟病 或其他病的出現機會亦相應減低。Okada 和Iseki (1990)作了一個延續十年的僱員健體計劃, 其中包 括健康護理（驗身、體能测試和健康講座）和健體 課程。結果証明長期的健體計劃對僱員的體能健康 有明顯的改善。Bernacki \& Baun (1984)亦指出僱員 對健體計劃的依附與其工作表現有著直接的相關。 在推行一個為期七個月的健體計劃後, Halfon, Rosenfeld, Ruskin \&Tenenbaum (1990)發現有參與 運動的一組僱員比沒有參與運動的一組在工作負 荷、心理疲勞、生理疲勞和工作滿足上都有明顯的 改善。

以下是過往的僱員健體計劃對公司實際效益上的 証明：

\section{僱員的缺席率}

在十三個有關僱員健體計劃的研究中, Shephard (1990) 發現僱員的缺席率平均下降了 $33 \%$ ，而每年的平均缺席亦下跌了 1.8 天。在 Canada Life Program 的僱員健體及康樂計劃的參 加者中, 其中百份之四十二顯示出僱員缺席率下降 了(Wanzel, 1982)。

\section{效益成本比例 (Benefit/cost ratio)}

效益成本比例是用來計算僱員健體計劃的經濟 得益。效益成本比例是指支出( 減低醫療開支、降 低缺席率等效益中所節省的金錢) 和成本 (推行計劃 的支出)之比例。例如 : 3.43 的效益成本比例表示 每\$1.00的支出有 $\$ 3.43$ 的回報。Gettman (1996); Messer and Stone (1995) 及Nordstrom (1988)指出在 不同的研究中, 有 0.76 至5.52的效益成本比例。

\section{僱員的土氣}

運動可以起到鼓舞士氣、舒發沉悶和解放困擾與 憂慮的作用。健體運動的參與者通常會表示有 “較 佳的感覺”。由於管理階層推行僱員健體計劃而提 高了員工的士氣, 其身體健康亦間接地受到心理上 改善的影響(Shephard, 1990)。

\section{僱員的生產力}

Shephard (1990) 指出人的體能跟其生產力有直 接的關係。工人參加有氧運動的訓練, 心肺耐力 會因而增強, 在執行機械操作的工序時, 雖然要 緊隨機器的節奏, 仍不會過早出現疲勞, 生產力 亦相應提高。Groves (1981) 亦發現健體計劃會改善 僱員的生產力和工作上的滿足感, 這對他們組織 和領導才能上亦有一定的幫助。

\section{僱員的流失}

Shephard (1990) 指出減低人材的流失, 對公司 的盈利有一定的貢獻, 然而實際的收益要視乎員 工參加健體計劃的情況。Wanzel (1982) 發現在云 云參加Canada Life Program 的公司中, 員工的流 失下降至 $1.5 \%$ 。

\section{僱員健體評劃的障礙}

\section{已被碓認的妨碳因素}

\section{參與者的凝聚性}

Shephard (1988) 指出通常有百份之二十的僱員 會是最初參加健體計劃的一群, 但最後只有一半 會變成長期的參與者。所以, 如何招攬和保留參 加者, 是推行健體計劃時最難於解決的問題 (B a u n \& Bernacki, 1988)。

Ruskin \& Bronner (1994)証明了健體計劃可以 增進參加者的身心健康, 但最終留下來的只有百 份之四十一。Canada Life Assurance Company 的 511 位有回應的僱員中, 有392 位參與了計劃, 但 其中有 170 人半途而廢(Leatt, Hattin, West \& Shephard, 1988)。

\section{場地及設施}

Shephard (1988) 指出 “缺乏適當的設施”, 是在 不常參與運動的一群中第二種常用的借口。在妨礙 參與健體計劃的因素中, 場地的大小被列為第二 位, 僅次於工作(Searle \& Jackson, 1985)。高質素的 設施會提高健體計劃的參與程度, 但巨大的投資卻 是僱主的一項負擔(Searle \& Jackson, 1985)。“擠迫 的場地” 和 “器材的價錢”, 在十五種妨礙因素 中, 分佔第三及四位 Jackson, 1983)。

健體的場地應位於方便的地點, 以方便僱員工 餘進行運動為原則(Stone, 1995)。Jackson (1983) 發現 有 $31.3 \%$ 的回應者覺得場地的方便與否是一項 “經 常性的因難”。而 “交通不便”和 “場地的位置” 亦被(Jackson, 1983)納入十五種妨礙因素之列。

\section{家庭責任}

家庭的責任, 無論在上班前或後, 對在職父母 (以母親為甚)，都會構成一定的阻礙 (Yardley, 1988)。Jackson (1983)指出 $15.9 \%$ 之的僱員認為家庭 責任是妨礙因素之一。 
知識和意念

要推動僱員去參與健體計劃, 先要其確認健體 活動的重要性(Ruskin et al, 1990)。Willee (1974); Stone (1995)建議要進行綜合性的呚育和康樂課程 去啟發僱員對健體活動的興趣。Morgan, Shephard, Finucane, Schimmelfing \& Jazmaji (1984)指出如果 僱員能認知運動的好處而改變其生活方式, 健體 運動的出席率亦會相應提高。

要達到理想的效益, 只是令僱員加入課程做運 動是不足夠的, 更重要是對其灌輸正確的健康信 念(Shephard, 1988)。對開始引進健體計劃的機構來 説, 最大的挑戰是要改變整間機構的風氣, 使僱 員對運動產生自發性的需求和責任 (B a u n \& Bernacki, 1988)。

縱使僱主或上層已確信健體計劃的效益, 如執 行者 (經理們) 未被同化, 推行的過程中仍可能 產生間接的阻力 $(\mathrm{AFB}, 1992) 。$

\section{僱主/管理階層的支持}

各工商機構的首要目的都是為了賺錢，其次 是製造就業機會和增進社會的繁榮, 僱員的健康 就往往會被忽視(Baun \& Bernacki, 1988)。Yardley (1988)指出無論在有沒有健體計劃的公司內, 上層 支持不足都是主要的妨礙因素。僱主支持與否, 直接在人力資源和行政運作上影響僱員健體計劃 的推行 $(\mathrm{AFB}, 1992)$ 。

成功的僱員健體計劃是要在公司內建立一種風 氣, 使僱員將健體意識作為自己的理想和責任。 這是需要公司內各管理階層長期的努力, 才可收 到成果的(Baun and Bernacki, 1988)。

\section{金 錢}

金錢往往是令人們不參加健體運動的第一主要 障礙(Henderson, Stalnaker \& Taylor, 1988) 。Jackson (1983) 亦指出有百份之十七的回應認為入場費會影 響他們參與健體活動的興趣。

\section{課程質素和師資}

學員持續參與課程的興趣深受課程的內容和導 師的領導才能所影響(Shephard, 1988)。資歷較好的 導師可保障參加者的安全和在需要時提供適當的 協助和指引。沒有正確的回饋, 學員會較易出 錯, 進度未如理想, 退出率亦會因而提高 $(\mathrm{A} \mathrm{F} \mathrm{B} \mathrm{,}$ 1992)。

\section{公司的資源}

資金不足是推行健體計劃的最主要的問題，而 其他人力和物質短缺的困難亦會因而產生 (Yardley, 1988)。
另一個常見的問題是沒有適當的地方去推行健 體計劃, 這通常出於撥款不夠和缺乏上層的支持, 無論由現有的地方改裝或新置, 都在為公司財政添 上負擔(Yardley, 1988)。

能否任用專業人士去推行僱員健體計劃, 是導 致成功的先決條件。規模較小的公司, 雖不能聘請 專業人士在公司內任職，亦應採納專家的意見去協 助和配合自己內部員工的運作 $(A F B, 1992)$ 。

\section{時 間}

Shephard (1988)指出 “時間不足” 是最常見的不 能參與運動的原因。Yardley (1988)發現百份之五十 的回應認為“時間”是極大的妨礙。時間因素是對 參與運動的第二個最嚴重的影響( H e n d e r s o n , Stalnaker \& Taylor, 1988)。午餐時間太短會令僱員 不能利用工餘的空間去參與運動(Stone, 1995)。

\section{業務的種類}

Yardley(1988)報告指有百份之五十的公司認為業 務的種類會妨礙僱員參與健體運動。其實這亦與員 工的類型有關, 如業內的僱員多數是女性, 結果便 與性別和家庭責任有關; 如工作性質是體力勞動 的, 或是員工的工資較低, 對參與健體運動的興 趣, 有一定的影響。

\section{工作任務}

Jackson (1983)發現員工的工作對參與健體計劃 的影響最大。在 2425 人中之有 $32.3 \%$ 認為工作責任 是 “經常性的困難”。工作的需要是一項常見的阻 礙, 它有幾個相關的成因。其中有午膳時間太短、 工作時間太長、輪班工作和沒有彈性上班時間等 (Yardley, 1988)。Stone (1995)指出許多的藍領工人 因為工作後覺得太累而不想做運動。

\section{始礙因素的範圍和分類}

要將所有影響參與健體運動的因素作統一的分 類是十分困難的。Jackson (1988)指出在以往一些個 別的研究中, 所採用的因素數目由四個到五十五個 不等。再者, 曾被納入研究之列的更超過一百項, 而最常見的有五類: 興趣、時間、金錢、設施/機會 及技術/能力(Jackson, 1983)。

研究者亦會採用不同的方法去發表其結果。有 些將所有因素并列而出。亦有些學者試圖用有系統 的概念法(Conceptual Method)和實驗法(Empirical Method)去分析。Jackson (1988) 指出個別的研究者 會用不同的概念去分類。試列表比較如下： 
表一 不同概念的分類法比校表

\begin{tabular}{ll}
\hline \multicolumn{1}{c}{ Researchers } & Classification \\
\hline Francken and van Raaij (1981) & internal vs external \\
Jackson and Searle (1985) & personal vs social \\
Crawford and Godbey & intrapersonal vs interpersonal \\
Jackson and Searle (1985) & blocking vs inhibiting \\
Boothby et al (1981) & absolute vs relative \\
Iso-Ahola and Mannell (1985) & permanent vs temporary \\
\hline
\end{tabular}

概念法分類是極為常用的, 但其流弊在於研究者 的主觀性而產生分析上的偏差, 不同的研究間亦難 作比較。因此, 部份的研究者則轉向於實驗法：一 個被認為較客觀的分類方法。

在過往的研究中, 因子分析法(Factor Analysis)是 將所要審定的項目作實驗化的分析而得出有系統的 因子分類。它是數學上的一種有用的方法, 但在不 同的研究中各項因素會因數據不同而令得出的分類 有所差異(Jackson, 1988)。

\section{總 結}

踓然, 僱員健體計劃的好處有目共睹, 但在推 行的過程中卻有一定的阻礙。計劃能否順利推行和 帶出其最大的效益, 則完全依靠僱主或高級管理階 層的支持和僱員的參與。要提高健體計劃的質素, 經理們和策劃者應作有系統探討和研究(Lankford, Degraaf \& Neal,1996)。

\section{References}

Association for Fitness in Business. (1992). Guidelines for employee health promotion programs. Champaign, IL: Human Kinetics Publishers.

Baun, W, B. \& Bernacki, E. J. (1988). Who are corporate exercisers and what motivates them? In Dishman, R. K.(Eds.), Exercise adherence: Its impact on public health (pp. 321-348). Champaign, IL: Human Kinetics .

Bernacki, E. J. \& Baun, W. B. (1984). The relationship of job performance to exercise adherence in a corporate fitness program. Journal of Occupational Medicine, 26(7), 529-531.

Bouchard, C., Shephard, R. J., Stephens, T., Sutton, J. R., McPherson B.D. (Eds.). (1988). Exercise, fitness, and health: The consensus statement. Exercise, fitness, and health : A consensus of current knowledge. Champaign, IL: Human Kinetics.
Gettman, L. (1996). Economic benefits of physical activity. Physical Activity and Fitness Research Digest. 2,(7), 1-6.

Greenberg, J. S., (1993). Comprehensive stress management. Dubuque, IA: Wm. C. Brown Communications.

Groves, D. L. (1981). Impact of industrial recreation upon job-satisfaction and productivity. Journal of Environmental Systems, 11(2), 187-200.

Halfon, S. T., Rosenfeld, O., Ruskin, H., \& Tenenbaum, G. Daily physical activity program for industrial employees. In Masahiro Kaneko.(Ed.), Fitness for the Aged, Disabled, and Industrial worker (pp. 260265). Champaign IL: Human Kinetics.

Henderson, K. A., Stalnaker, D., Taylor, G. (1988). The relationship between barriers to recreation and gender-role personality traits for women. Journal of Leisure Research, 20(1), 69-80. 
Jackson, E. L., (1983). Activity-specific barriers to recreation participation. Leisure Sciences, 6(1), 4760.

Jackson, E. L., (1988). Leisure constraints: A survey of past research. Leisure Sciences, 10, 203-215.

Lankford, S., DeGraff, D., \& Neal, L. L., (1996). A comparison of barriers to leisure and sport activity participation in the United States: Implications for Hong Kong. Hong Kong Recreation Review, 8, 43-46.

Leatt, P., Hattin, H., West, C., \& Shephard, R. J. (1988). Seven year follow-up of employee fitness program. Canadian journal of public health, 79(1), 20-25.

Messer, J., Stone, W. (1995). Worksite fitness and health promotion benefit/cost analysis: A tutorial, review of literature, and assessment of the state of the art. AWHP is Worksite Health, 2, 34-43.

Morgan, P. P., Shephard, R. J., Finucane, R., Schimmelfing, L., \& Jazmaji, V. (1984). Health beliefs and exercise habits in an employee fitness programme. Canadian Journal of Applied Sport Sciences, 9(2), 87-93.

Nordstrom, G., (Ed.) (1988). Can employee fitness cut health costs? Recreation, Sports \& Leisure, 8(6), 57-59.

Okada, K. \& Iseki, T. (1990). Effects of a ten-year corporate fitness program on employees' health. In Masahiro Kaneko.(Ed.), Fitness for the Aged, Disabled, and Industrial worker (pp. 249-253). Champaign IL: Human Kinetics.

Ruskin, H., Bronner, S. (1994). Effects of eight years of physical activity on health and behaviour of industrial workers. Journal of the International Council for Health, Physical Education and Recreation, Sport and Dance, 30(4), Summer 1994, $22-25$.

Ruskin, H., Halfon, S. T., Rosenfeld, O., \& Tenenbaum, G. (1990). The effect of a daily exercise program of industrial employees on selected physical fitness components. In Masahiro Kaneko.(Ed.), Fitness for the Aged, Disabled, and Industrial worker (pp. 254259). Champaign IL: Human Kinetics.

Searle, M. S., Jackson, E. L. (1985). Socioeconomic variations in perceived barriers to recreation participation among would-be participants. Leisure Sciences, 7(2), 227-249.

Shephard, R. J. (1988). Exercise adherence in corporate setting:Personal traits and program barriers. In Dishman, R. K. (Eds.), Exercise adherence: Its impact on public health (pp. 305-319). IL: Human Kinetic.

Shephard, R. J. (1990). The costs and benefits of exercise: An industrial perspective. In Masahiro Kaneko.(Ed.), Fitness for the Aged, Disabled, and Industrial worker (pp. 189-204). Champaign IL: Human Kinetics.

Shephard, R. J. (1996). Worksite fitness and exercise program:A review of methodology and health impact. American journal of Health Promotion, 6, 292-301

Stone, R. J. (1995). Human Resource management. Milton, Australia: John Wiley \& Sons.

Wanzel, R. (1982). Employee health and fitness in Canada. Employee fitness: an investment in your human resources. Melbourne: Dept. Of Youth, Sport and Recreation.

Willee, A. W. (1974). Recreation and industry. Australian Journal of Health, Physical Education and Recreation, 74,20-28.

Yardley, J. K. (1988). Barriers to employee wellness programs in Ontario corporations:A summary of the major findings and recommendations. Ontario, Canada : Brock University, Department of Recreation and Leisure Studies.
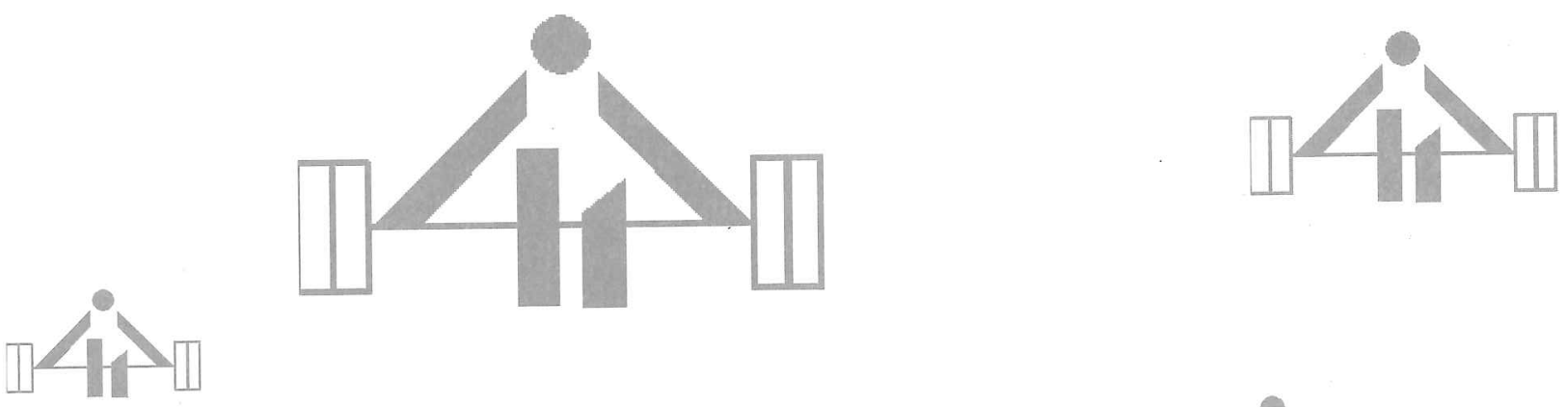